\title{
MODELLING LAND COVER CHANGE IN A MEDITERRANEAN ENVIRONMENT USING RANDOM FORESTS AND A MULTI-LAYER NEURAL NETWORK MODEL
}

\author{
Elias Symeonakis \\ School of Science and the Environment, Manchester Metropolitan University, UK - \\ E.Symeonakis@mmu.ac.uk
}

\begin{abstract}
The present study seeks to identify the changes that have taken place in the Mediterranean island of Lesvos (Greece) between 1995 and 2007 in the seven main land cover types of the island. We also attempt to predict the changes that will occur by the year 2019. Three Landsat 5 TM summer scenes were used spanning 12 years. A combination of Random Forests (RF) classification with expert rules was then applied for achieving high overall classification accuracies $(95 \%$, $94 \%$ and $91 \%$, respectively). The 1995 and 2001 classified data were then used to train a multi-layer perceptron neural network (MLPNN) model and predict land cover for the year 2007. Seven possible transitions were included in the MLPNN model which was trained with the 1995 and 2001 classified data successfully: accuracy rate of $93 \%$ after 5000 iterations. The quantity of change in each transition was modelled through Markov chain analysis. The modelling results for 2019 provide an anticipated prediction for the end of the decade: economic activity will remain centred to the agricultural sector, as crops and olive groves will expand. A rather unanticipated prediction is the significant increase in the area of forests.
\end{abstract}

Index Terms - Landsat, Land cover change, Random Forests, Neural Networks, Markov chain analysis

\section{INTRODUCTION}

Current rates, extents and intensities of land-use and landcover change (LULCC) are driving important changes in ecosystems and environmental processes at local, regional and global scales. These changes encompass some of the greatest environmental concerns of today, including climate change, biodiversity loss and the pollution of air, land and water. Mapping, monitoring and modelling LULCC has therefore, become a major priority of researchers and policymakers around the world. To this end, Earth observation (EO) data and geoinformation technologies and analysis techniques are now commonly applied as they provide a combination of fine spatial and temporal resolutions and increasingly accurate mapping [1] [2] [3] [4] and promising change modelling results [5]. However, change detection based on satellite data is still a difficult task to perform [6]. The present study seeks to identify the changes that have taken place in the Mediterranean island of Lesvos (Greece) between 1995 and 2007 in the seven main land cover types of the island, namely: (i) bare (B), (ii) urban, (iii) scrubland and Mediterranean maquis, (iv) olive groves, (v) other crops (irrigated and non-irrigated), (vi) forests (coniferous and deciduous), and (vii) water bodies. We also attempt to predict the changes that will occur by the year 2019.

\section{METHODOLOGY}

\subsection{Datasets}

Three Landsat 5 TM summer scenes were used (July 1995, June 2001 and August 2007) spanning 12 years. Other ancillary datasets included a 30-m Digital Elevation Model (DEM); black-and-white 1:33,000 aerial ortho-photos of 1995; the CORINE land cover maps of 1990 and 2000; a map of the Natura 2000 protected areas; a multi-spectral QuickBird 2000 image with a nominal pixel size between $2.44 \mathrm{~m}$ and $2.88 \mathrm{~m}$ (at nadir), resampled at $3 \mathrm{~m}$. Furthermore, Google Earth was also employed which covers the study area with multi-temporal QuickBird fused multi-spectral and panchromatic data (61 to $72 \mathrm{~cm}$ pixels at nadir).

\subsection{Land cover mapping and modelling}

The imagery were first ortho-rectified to sub-pixel precision (total RMSEs $<20 \mathrm{~m}$ ) and then corrected for the removal of topography-related shadows present in large areas of the original data. A combination of random forests classification with expert rules was then applied for achieving high overall classification accuracies. The expert rules, devised by [7] are based on a division of the area into five zones according to their physical properties, such as topography, geomorphological characteristics and dominant vegetation types.

The 1995 and 2001 classified data were then used to train a multi-layer perceptron (MLP) neural network model and predict land cover for the year 2007. First, the explanatory power of the variables that lead to change was examined. The 
chosen variables were then added to the model either as static (e.g. elevation, slopes) or dynamic (e.g. distance from roads) components. After that, each transition was modelled with the MLPNN model producing a transition potential map for each transition. In the last stage, the quantity of change in each transition was modelled through Markov chain analysis. Constraints were included such as the protected areas of the Natura 2000 network and weights were assigned to every variable. The modelled land cover data for 2007 were then compared to their estimated counterpart in order to assess the capability of the model to predict future changes. Finally, the classified data of 1995 and 2007 were used for training the MLPNN model and for predicting the future land cover of the island in 2019.

\section{RESULTS}

Table 1 summarises the results of the Random Forests (RF) classifications and rule-based corrections for 1995, 2001 and 2007, as well as the modelled figures for 2007 and 2019. RF overall classification accuracies were high for all images: 95\%, 94\% and 91\%, respectively. User's and producer's accuracy figures were also high for all cover types (ranging from $82 \%$ for scrubland and maquis to $99 \%$ for water bodies).

\begin{tabular}{|c|c|c|c|c|c|}
\hline \multirow{2}{*}{\begin{tabular}{c} 
uand \\
\cline { 2 - 6 }
\end{tabular}} & $\begin{array}{c}\mathbf{1 9 9 5} \\
\text { RF } \\
\text { (pixls) }\end{array}$ & $\begin{array}{c}\mathbf{2 0 0 1} \\
\text { RF } \\
\text { (pixls) }\end{array}$ & $\begin{array}{c}\text { RF } \\
\text { (pixls) }\end{array}$ & $\begin{array}{c}\text { MLPN } \\
\text { N } \\
\text { (pixls) }\end{array}$ & $\begin{array}{c}\text { MLPN } \\
\text { N } \\
\text { (pixls) }\end{array}$ \\
\hline Bare & 21124 & 18883 & 17720 & 18883 & 18883 \\
\hline Urban & 20535 & 25094 & 25751 & 25094 & 25094 \\
\hline $\begin{array}{c}\text { Shrub } \\
\text { s and } \\
\text { maqui } \\
\text { s }\end{array}$ & 739083 & 722576 & 729031 & 723515 & 703502 \\
\hline $\begin{array}{c}\text { Olive } \\
\text { groves }\end{array}$ & 1267959 & 1278875 & 1277633 & 1271088 & 1280626 \\
\hline $\begin{array}{c}\text { Cultiv } \\
\text { ated } \\
\text { land }\end{array}$ & 93697 & 101610 & 102824 & 114030 & 105788 \\
\hline $\begin{array}{c}\text { Forest } \\
\text { s }\end{array}$ & 431805 & 426588 & 420506 & 421016 & 439733 \\
\hline $\begin{array}{c}\text { Water } \\
\text { bodies }\end{array}$ & 9509 & 9671 & 9832 & 9671 & 9671 \\
\hline
\end{tabular}

Table 1. Number of pixels covered by each land cover type, as estimated by Random Forests (RF) classification (1995, 2001, 2007) and by the multi-layer perceptron neural network (MLPNN) land cover change model $(2007,2019)$

Seven possible transitions (olives to scrubs; forests to scrubs; forest to olives; crops to olives; scrubs to olives; scrubs to crops; scrubs to forest) were included in the MLPNN model which was trained with the 1995 and 2001 classified data successfully: accuracy rate of $93 \%$ after 5000 iterations. Figure 1 is the 2007 land cover map produced by RF and the MLPNN model: a good spatial agreement is apparent. A validation of the latter against the RF 2007 map produced an overall correct figure of $98.5 \%$, a kappa statistic of 0.98 , an agreement in location of 0.65 , a disagreement in quantity of 0.002 and a disagreement in location of 0.01 .

\section{DISCUSSION}

When modelling LULCC it is important that the model is trained using highly accurate input data. The Landsat TM imagery were carefully chosen so that they belonged to the same phenological period and were pre-processed to remove radiometric and geometric mismatches. To further improve results, expert rules were applied to the RF classification outputs to correct for omission and commission errors. The final land cover classifications were highly accurate and show the importance of the agricultural sector for the island: olive groves and crops occupy more than $50 \%$ of the islands surface. Although a number of olive groves are being abandoned in the higher lands, a larger number of new plantations appeared between 1995 and 2007 in the lowlands, which proves the strong link between the islands economy and the olive-related products, such as oil, olives, soap, etc. The small but steady increase in the urban land use was identified. Forested areas are fewer in 2007 than in 1995, which reflects the effect of human and natural disturbance through illegal clearings and forest fires.

Modelling the LULCC in 2007 was fairly accurate in terms of the spatial coverage of the different types. A general agreement between the RF estimate and the MLPNN model output can be seen in all areas (Figure 1) except for two obvious differences: areas ' 1 ' and ' 2 ' in purple and red circles in Figure 1. The latter is actually a forested area which was burned in 2006, and which the model was unable to pick up.

According to the validation results, there was a high agreement in terms of the quantity of change but relatively small in terms of the qualitative change. In general, both the high quantity agreement and the low disagreement figures of quantity and location, can be attributed to the fact that we only modelled the transitions due to anthropogenic disturbance.

The long term modelling results for 2019 provide an anticipated prediction for the end of the decade: economic activity will remain centred to the agricultural sector, as crops will expand by $3.8 \mathrm{~km}^{2}$ and olive groves by $1.6 \mathrm{~km}^{2}$. A rather unanticipated prediction is the significant increase in the area of forests $\left(17 \mathrm{~km}^{2}\right.$ extra). Finally, the unchanged urban land cover is probably due to the lack of information layers that would guide the model into such expansion, e.g. state motivation measures (e.g. tax cuts), long term strategic plans (e.g. expansion of existing road network, building of new ports or expansion of old ones), etc.

\section{CONCLUSION}

EO data are very important for the mapping, monitoring and modelling of LULCC. Landsat TM data were successfully used here for mapping the land cover change that occurred 
between 1995 and 2007 in the Mediterranean island of Lesvos (Greece). A number of separability issues were dealt with post-classification and the changes identified verify that

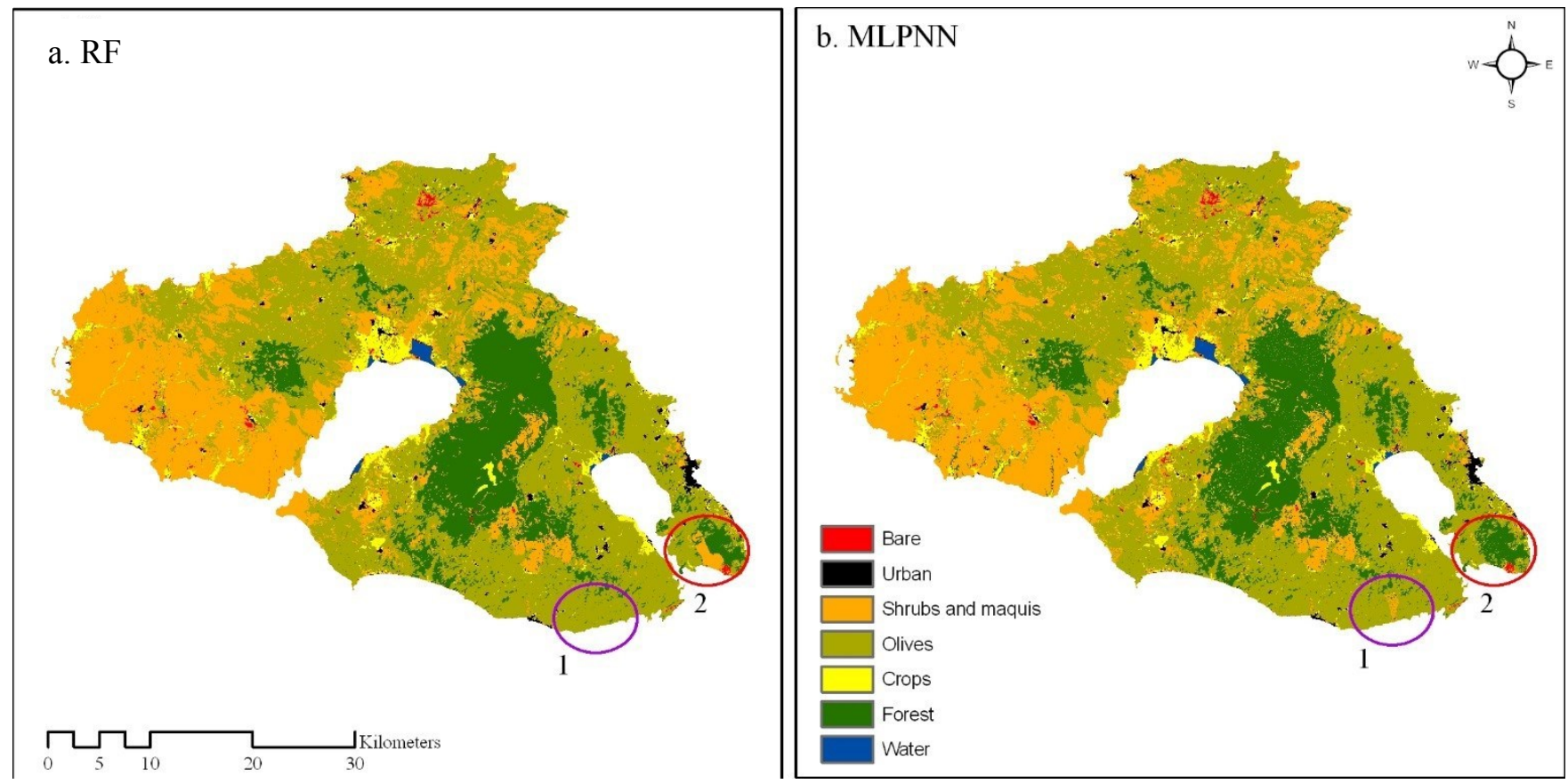

Figure 1. (a) Random Forests (RF) estimate of land cover and (b) multi-layer perceptron neural network (MLPNN) model estimate for 2007. Areas in circles are obvious differences.

the main economic activity of the island i.e. agriculture, is driving these changes. The classified data were used to train and validate a multi-layer perceptron neural network model. The results were promising in terms of the prediction of the quantities of change, but not the specific qualitative prediction, i.e. to which land cover type the estimated changes will occur. Further research is currently underway for identifying more underlying factors of change in the island.

\section{ACKNOWLEDGEMENTS}

Elias Symeonakis is supported by an EU FP7 Marie Curie Career Integration Grant (PCIG12-GA-2012-3374327).

\section{REFERENCES}

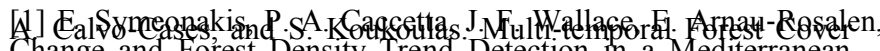
Change and Forest Density Trend Detection in a Mediterranean Environment. Land Degradation \& Development. DOI: 10.1002/ldr.2405, 2015.

[2] C. Huang, S. Kim, A. Altstatt, J.R.G. Townshend, P. Davis, K. Song, C.J. Tucker, O. Rodas, A. Yanosky, R. Clay and J. Musinsky, "Rapid loss of Paraguay's Atlantic forest and the status of protected areas -A Landsat assessment", Remote Sensing of Environment, 106, pp.460-466, 2007

[3] R.E. Kennedy, W.B. Cohen and T.A. Schroeder, "Trajectorybased change detection for automated characterization of forest disturbance dynamics", Remote Sensing of Environment, 110, pp.370-386, 2007

[4] E. Symeonakis, P.A. Caccetta, S. Koukoulas, S. Furby and N. Karathanasis, "Multi-temporal land cover change mapping with Landsat data applied to the Mediterranean island of Lesvos (Greece)", International Journal of Remote Sensing, 33(13), pp. 4075-4093, 2012.

[5] P.H. Verburg, P.P. Schot, M.J. Dijst and A. Veldkamp, "Land use change modelling: current practice and research priorities", GeoJournal, 61(4), pp.309-324, 2004

[6] P. Coppin, I. Jonckheere, K. Nackaerts, B. Muys and E. Lambin, "Digital change detection methods in ecosystem monitoring: a review", International Journal of Remote Sensing, 25 (9), pp. 15651596,2004

[7] E. Symeonakis, N. Karathanasis, S. Koukoulas, and G. Panagopoulos. Monitoring sensitivity to land degradation and desertification with the environmentally sensitive area index: the case of Lesvos island. Land Degradation \& Development. DOI: 10.1002/ldr.2285, 2014. 